\title{
THE APPLICATION OF JAPANESE CANDLESTICK CHARTING ON THE RESIDENTIAL REAL ESTATE MARKET
}

\author{
Anna Gdakowicz, PhD \\ Institute of Econometrics and Statistics \\ University of Szczecin \\ e-mail:alatko@wneiz.pl
}

\begin{abstract}
The real estate market is regarded as a part of the capital market. Just as they invest in securities, investors allocate their funds in real estate, hoping to make a sound profit. There are many tools that support the process of investing on the stock exchange, such as a technical analysis. There are also proven methods that help predict future prices of assets on the basis of their historic quotations.

The article is an attempt to transfer the Japanese method of candlestick charting used in the technical analysis of securities onto the real estate market. The method has been implemented on the residential real estate market due to the relatively large number of transactions being concluded there.
\end{abstract}

Key words: Japanese candlestick charting, residential real estate market, price trends.

JEL Classification: G12, R32.

Citation: Gdakowicz A., 2014, The application of Japanese candlestick charting on the residential real estate market, Real Estate Management and Valuation, vol. 22, no. 4, pp. 27-34.

DOI: $10.2478 /$ remav-2014-0034

\section{Introduction}

The real estate market is one of the elements of the capital market and thus investments in real estate can be an alternative to investing in securities. On organized capital markets, players seek support in making their investment decisions from technical and/or fundamental analysis.

Technical analysis uses charts to deal with price and sales volume analyses and forecasts. It is based on the premises that (MURPHY 1999):

1) market action discounts everything,

2) prices move in trends,

3) history is likely to repeat itself.

The first assumption is that a price reflects all the drivers - either fundamental, political or psychological - that are relevant to a given good. Prices are the effect of demand and supply. When supply outweighs demand, prices go up, and vice versa - when supply is larger than demand, they go down.

The second assumption - that prices move in trends - is of fundamental importance to technical analysis. All prices move in certain directions. It is believed that price movements are more likely to follow a current direction than to change it.

The third assumption - that history is likely to repeat itself - is essential for forecasting future prices on the basis of the performance of securities, which means that we can predict the future on the basis of the past.

Fundamental analysis assumes that the price of a purchased good is affected by its economic and political environment. External factors shaping demand and supply have an effect on the investment value as well. If the value is higher than the price of a commodity, the commodity is undervalued and 
thus worth buying, because its price is likely to increase soon. And conversely, a price that is higher than the value of the good means that it is overvalued, which is a signal that it should be sold, because its price is going to fall. Fundamental analysis focuses on the reasons why a price is as it is.

So, the question is whether methods applied in technical analysis can be used for the real estate market. Technical analysis methods are based on a detailed examination of price charts, as well as on looking for characteristic formations heralding a market change or trend continuation. There are methods that are strictly related with chart analysis (e.g. the formations of trend reversal and continuation) and methods based on quantitative indices (e.g. moving averages, Bollinger bands, oscillators). Japanese candlestick charting falls into the first category. Other methods of future price estimation can be found in (ANGLIN, WIEBE 2013; BEŁEJ 2013; BERACHA, WINTOKI 2013; CHEN et al. 2012; GNAT 2011; KOKOT, BAS 2013; TROJANEK 2013).

\section{The historical background and construction of Japanese candlesticks}

The history of Japanese candlestick charting dates back to 17th century Japan. In those times only physical rice was being traded. Transporting rice between towns was difficult, so a specific type of rice market developed where traders used documents confirming that rice had been stored in a warehouse in another town. Then, Japanese feudal lords started issuing receipts for rice from future harvests, the so called empty contracts. It was the speculation with future rice contracts that became the basis for the Japanese technical analysis.

A fundamental contribution to the development of these methods was made by a rice trader by the name of Homma. He discovered that the price of rice is influenced not only by the volume of the future harvest, but also by the expectations, forecasts and speculations of the traders. He understood that there was a difference between the value and the price of rice (NISSON 1996). Homma collected historical records of rice prices from several decades and was the first to analyze prices from the past in order to forecast their future trends. Basing on this knowledge, he managed to make an enormous fortune.

For a long time Japanese candlestick charting was popular in Japan, but unknown to the Western world. Not until 1991 did Steve Nisson publish the first book about the method (NISSON 1991). Since then Japanese candlestick charting has become one of the most recognized methods of technical analysis (TARCZYŃSKI 1997). Its great advantage is that it can be used both independently and in association with other popular charting methods.

In order to construct a candlestick chart we need to know (just like in the case of other technical analysis charting) the open, close, high and low values for the time period we want to describe. The analyzed time interval can be freely modified. If the collected data allow, Japanese candlesticks can be presented on a daily, weekly, monthly or quarterly basis.

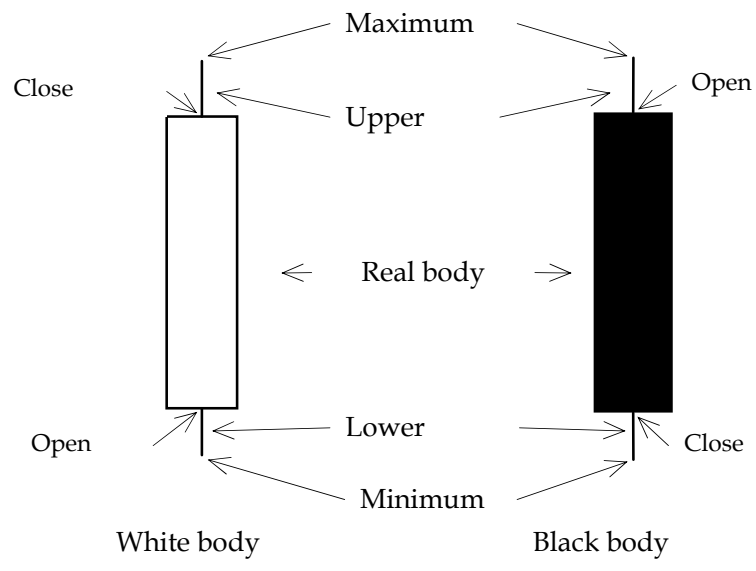

Fig. 1. Construction of Japanese candlesticks. Source: own study.

Candlesticks are composed of the real body (black or white) which represents the area between the opening and closing trades (Fig. 1). The white (hollow) real body means that the close was higher than the open (bull market), while the black (filled in) body means that the security closed lower than it opened (bear market). R. Novy-Marx calls the bull market a cold market (NOVY-MARX 2009). The colors of the candlesticks' real bodies enable us to instantly see the relation between demand and supply. Thin lines above and below the real body are called shadows or wicks. 
In candlestick charting, both single candlesticks and their formations are important. It is essential to know whether a candlestick's real body is large or small. A large discrepancy between the opening and closing price is called long days (Fig. 2), no matter if a candlestick's real body is black or white. Long real bodies often indicate that a trend is likely to reverse, particularly when the body is at least three times longer than the prior one. Short days (or spinning tops) are candlesticks describing a small difference between the close and the open. They indicate an indecisive market and no balance between supply and demand.

Another interesting pattern is doji candlesticks that illustrate sessions when the open and close are the same or almost the same. Doji are particularly important after a long upward or downward trend and can be indicative of a trend reversal. A doji with a long lower and upper shadow means that the market is indecisive. The longer the upper shadow of a doji, called a gravestone, the stronger the indication for a bearish market. A dragonfly doji has a long lower shadow, which forecasts an approaching bullish market.

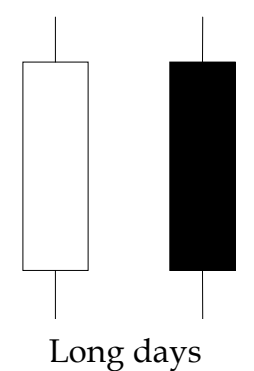

Long days

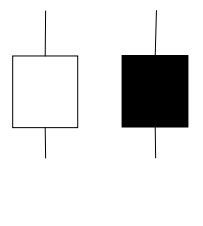

Short days

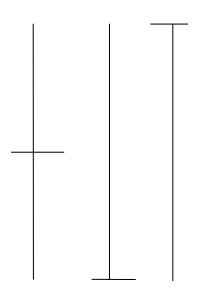

doji candles

Fig. 2. Types of candlesticks. Source: own study.

Although real bodies are considered the most important part of Japanese candlesticks, their shadows are significant as well. A long upper shadow forming in an upward trend indicates decreasing demand or strong supply, and is a prediction of low prices. A long lower shadow in a downward trend means that supply is running low, which leads to higher prices. A candlestick with both long shadows is called a high wave candlestick. It shows that the balance between sellers and buyers is unstable.

Japanese candlestick charting offers an array of candlestick patterns which visualize a trend reversal or continuation (NISSON 1991; NISSSON 1996; MURPHY 1999). The bullish reversal patterns include (Fig. 3):

1) a long white candlestick - a white candlestick gains significance when it is at least three times longer than the prior candle,

2) hammer - has a long lower shadow; after a strong downward trend it signals an upward reversal,

3) piercing pattern - composed of two candles: the closing price of a white candlestick's real body is located above the middle of the prior black candlestick's real body,

4) bullish engulfing pattern - significant when following a downward trend; composed of two candlesticks: a large white real body engulfs a small black real body in a downtrend.

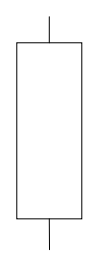

1

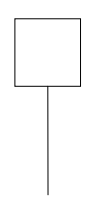

2

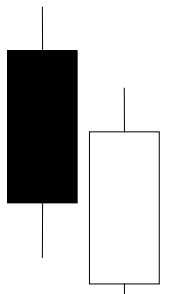

3

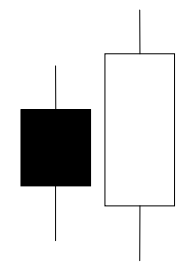

4

Fig. 3. Bullish reversal patterns. Source: own study.

The bearish reversal patterns include (Fig. 4): 
1) a long black candlestick - just as a white candlestick for the bullish market, a long black real body reflects a downward trend, especially when its body is at least three times longer than a prior candlestick's real body and occurs after a long uptrend,

2) hanging man - a candlestick with a very long lower shadow; it is an important signal of a trend reversal when appearing on the top of an upward trend,

3) shooting star - has a long upper shadow and forecasts a downtrend provided it appears following an uptrend and is confirmed by a bearish candlestick; can be either black or white,

4) dark cloud cover - consists of two candlesticks; the closing price of the black candlestick's real body is below the middle of the prior white candlestick's real body,

5) bearish engulfing pattern - composed of two candlesticks; significant when appearing after an uptrend; a black candlestick engulfs a prior white candlestick.

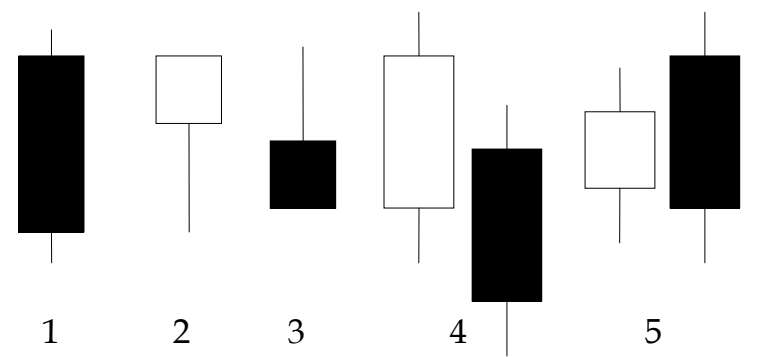

Fig. 4. Bearish reversal patterns. Source: own study.

\section{The use of the Japanese candlestick charting on the real estate market}

Technical analysis methods can be easily implemented on different investment markets. When planning to apply Japanese candlestick charting we have to meet only one condition, i.e. to know the lowest and the highest price of a given good in a given time interval. In the specific case of the real estate market, this condition has to be extended by the proper choice of the analyzed interval.

The author of this article uses Japanese candlestick charting to present the residential real estate market in Szczecin on the east bank of the Odra River. More and more often, dwellings are regarded not only as consumer staples, but also as investment opportunities. Their prices are determined by such factors as location or standard, and many others associated with the buyers' needs. On the other hand, the price of 1 square meter also depends on the buyers' expectations and forecasts concerning the flat's future value. The first group of factors is the subject of the fundamental analysis of the residential real estate market, while the second one (referring to price forecasting) is the domain of technical analysis.

When conducting technical analysis of the capital market we observe the price of a single security. In the case of the real estate market, one property can be traded only once in several decades. Therefore, analyses requiring a set of data concerning prices are made on the basis of prices of properties that are similar to the one we are interested in. In this article the author applies Japanese candlestick charting to the residential market, as it is the segment of the real estate market with the highest number of transactions. What is more, the data in this segment are better comparable than in any other. For the purpose of this analysis, the area of research was reduced to the eastern part of Szczecin, located on the right bank of the River Odra, where residential housing is relatively homogeneous (cooperative high-rise buildings). The research was based on data concerning individual transactions of flats concluded in the period of 1995-2002. The data came from the 3rd Tax Office in Szczecin. The analysis focused on the selling price of 1 square meter of sold flats. Two time intervals were proposed: a monthly and a quarterly one. The shortage of transactions made it impossible to choose weekly and daily prices for consideration.

The opening price was set at the price of 1 square meter of a flat quoted on the first day of the period under observation when a transaction took place. When there were several transaction in one day, the opening price was calculated as the arithmetic mean of the recorded prices of 1 square meter. The closing price was calculated on a similar basis - as the price recorded on the last day of the analyzed time interval or, when the number of transactions was larger than one, as the arithmetic mean of transactions concluded on the last day of the interval. The closing price of one time interval was not the same as the opening price of the next interval. The price maximum (minimum) was the highest (lowest) recorded price of one square meter of a flat in a given month or quarter. 
Fig. 5 shows a candlestick chart for the movement of prices of 1 square meter of a flat on the right river bank of Szczecin, calculated monthly during the period between January 1995 and December 2001.

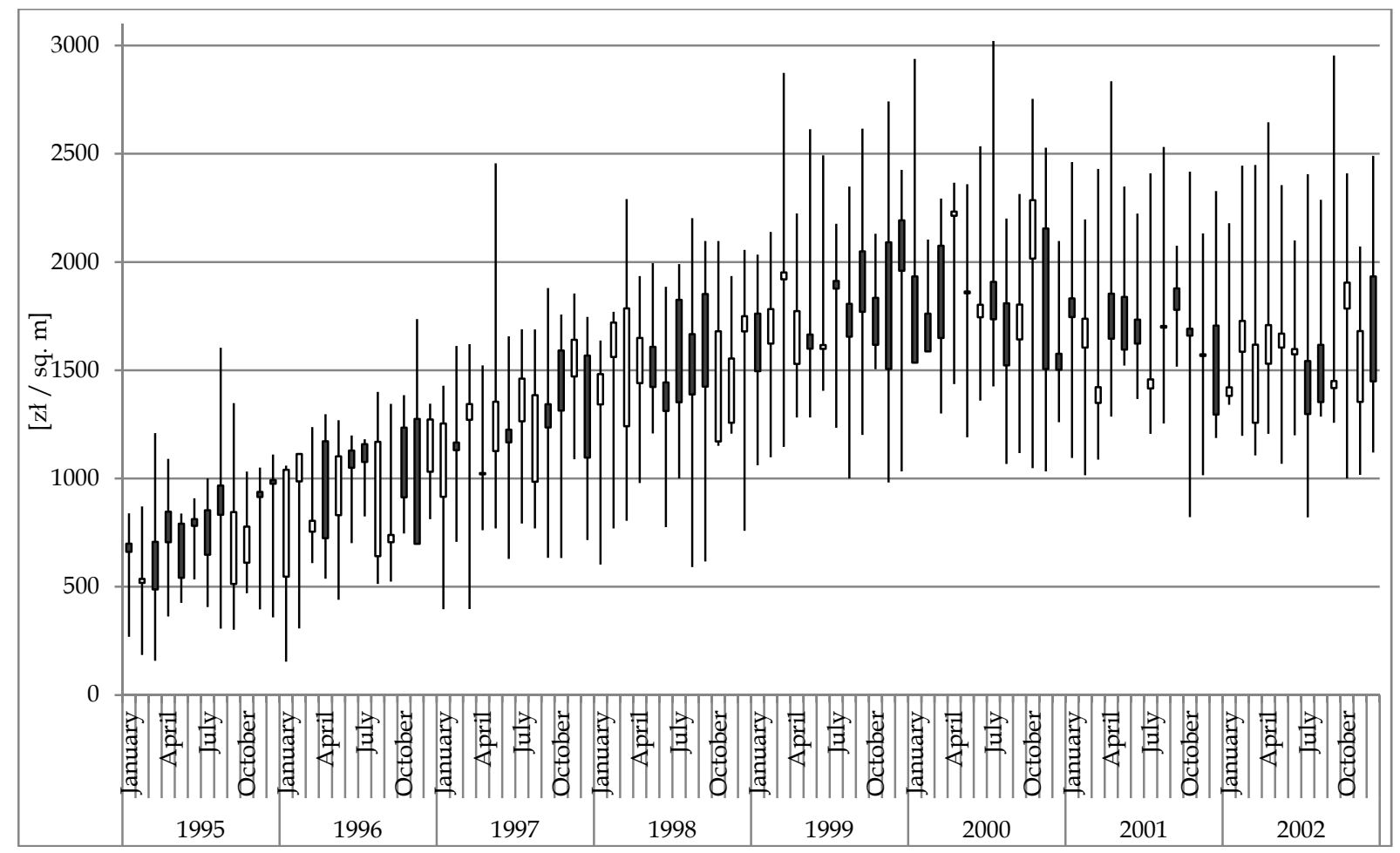

Fig. 5. Japanese candlestick charting used for the residential real estate market on the right river bank of Szczecin in 1995-2002 by month. Source: own study.

In the observed period, the residential property market was unstable, which is reflected by some of the candlesticks' long lower and upper shadows, or by high wave candlesticks. When the high wave candlesticks appear after a long trend (either upward or downward), we say that the market loses its sense of direction. Therefore, we can say that the analyzed market seemed to be disoriented throughout the entire observed period, which was additionally confirmed by the large number of spinning tops (i.e. candlesticks with short real bodies).

In Japanese candlestick charts made for the capital market, an upward or downward trend is clearly visible. When price is growing, there is a sequence of white candlesticks. And, conversely, it is black candlesticks that prevail in the downtrend. In the case of the residential real estate market, such a relationship does not exist. Early in the analyzed period (from August 1995), we can see a sequence of candlesticks with black real bodies (which indicates more sellers than buyers and foreshadows lower prices), with every consecutive candlestick climbing to a higher price level. An identical situation took place from May to September 1998 and from July to March 2000.

In Fig. 5 we can also observe the candlestick patterns listed above. In January 1996, there was a long white candlestick whose real body was three times longer than that of the prior one, which indicated an upward trend. The consecutive candlestick confirmed a rise in prices, but at the same time, signaled a drop in the next time interval (the hanging man pattern). More long white candlesticks appeared in August 1996 and March 1998.

The engulfing pattern, which predicts an uptrend, could be seen in April-May 1996, NovemberDecember 1996, June-July 1997, October-November 1997 and December 1997-January 1998.

Patterns signaling the bear market, i.e. the decrease in prices, were also recorded. The pattern of the dark cloud cover appeared in April-May 1999, April-May 2000, October-November 2001, June-July 2002. The bearish engulfing pattern was observed near the end of 1998 and at beginning of 1999.

At the beginning of the observed period, the majority of patterns indicated a rise in prices. Yet starting from 1999, there were more patterns signaling a bear market. 
When analyzing prices on residential real estate markets researchers often choose quarterly time intervals. Fig. 6 shows Japanese candlesticks illustrating the situation on the residential market on the right river bank of Szczecin in quarterly time intervals.

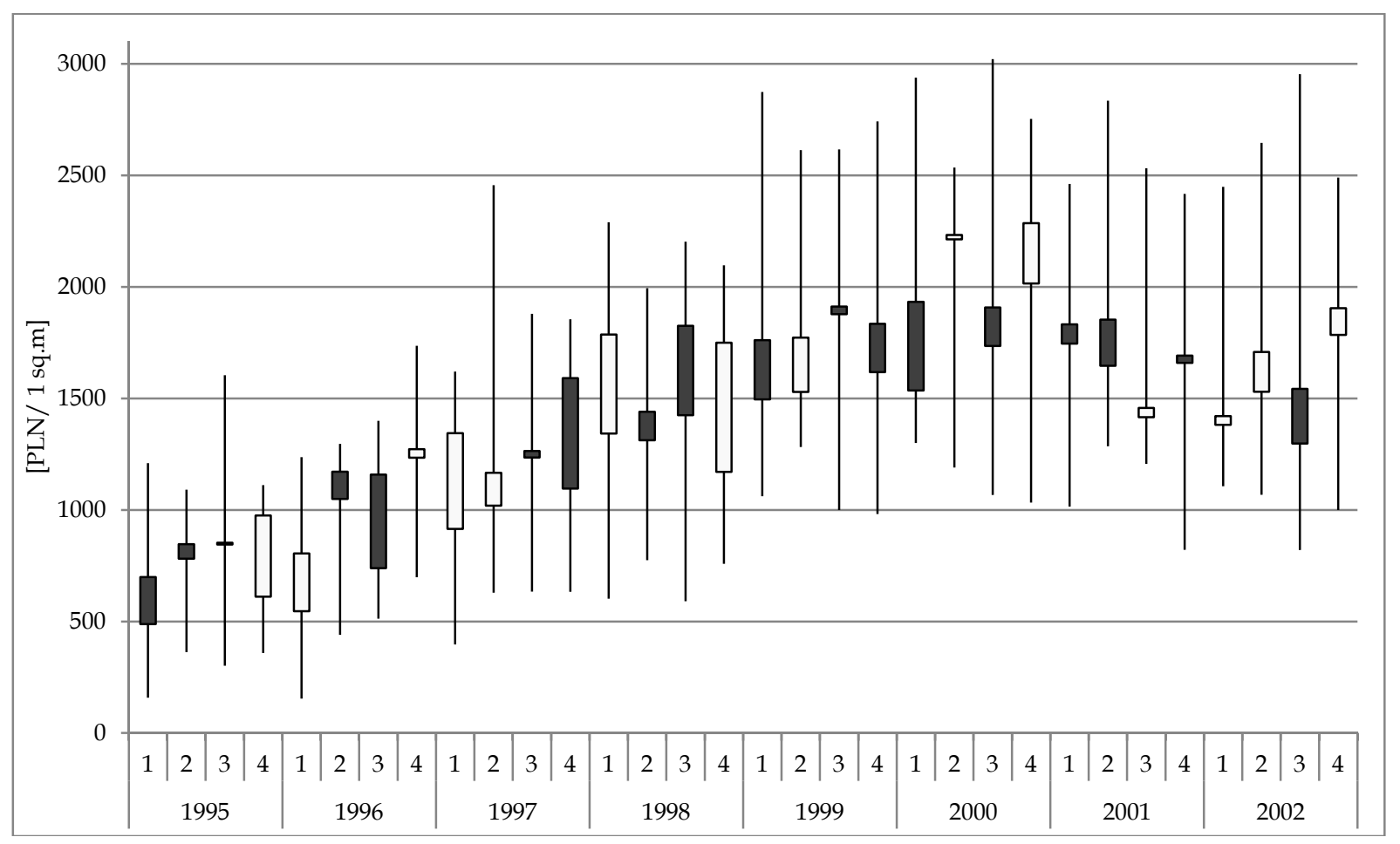

Fig. 6. The Japanese candlesticks of the residential real estate market on the right river bank of Szczecin in 1995-2002 in quarterly time intervals. Source: own study.

Similarly to the monthly data, in the case of quarterly time intervals we can see that high wave candlesticks prevailed, which means that the market was not stable. However, the aggregation of data made it possible to present the main trends in the prices of 1 square meter of a flat very clearly and to avoid blurring the picture with irrelevant information.

At the beginning of the observed time period (by the end of 1997) the prices of 1 square meter were growing, which was reflected by the bullish engulfing pattern ( $3^{\text {rd }} 4^{\text {th }}$ quarter of 1995$)$, the piercing pattern ( $3^{\text {rd }}-4^{\text {th }}$ quarter of 1996$)$ and the long white candlestick ( $1^{\text {st }}$ quarter of 1997$)$.

In the subsequent years, the market was highly indecisive. In one interval, the patterns indicated a bear market, only to show a reversed trend in the following - contrary to the public's expectations for prices to fall further. The dark cloud cover (1 $1^{\text {st }} 2^{\text {nd }}$ quarter of 1998) signaled a decrease in prices, but in the next intervals (3rd-4th quarter of 1998 and 1st-2nd quarter of 1999) the engulfing pattern appeared, heralding the arrival of a bull market. A similar sequence of price behavior could be seen at the end of the observation period. Initially, the dark cloud cover appeared (2nd-3rd quarter of 2002) only to be followed by the engulfing pattern (3rd-4th quarter of 2002). In contrast, the engulfing pattern was reported in the 3rd and 4th quarter of 2000 and changed to the dark cloud cover in the first three months of 2001.

\section{Conclusion}

Japanese candlestick charting is a method which is relatively easy to use because no complicated calculations are needed. Therefore, its advantage is that it is simple to draw and simple to read, even though some practice is needed in distinguishing patterns that signal the reversal of price trends. One glance at a Japanese candlestick chart and we can draw a number of conclusions concerning:

1) the movement of prices - are we dealing with an upward or a downward trend?,

2) price level,

3) movements of prices in particular intervals of time. Price quotations on similar levels (within a single time interval) are illustrated by candlesticks with short shadows. Wide fluctuations are represented by a candlestick with a long lower and upper shadow,

4) identification of non-typical objects that differ significantly from the rest of the set, 
5) the answer to the question if the analyzed market is bullish (white candles) or bearish (black candles),

6) trend reversals in the subsequent time intervals.

The application of Japanese candlestick charting in the technical analysis of the residential real estate market of new developments located on the right river bank of Szczecin leads to the conclusion that, in the analyzed period of time, this market was striving for balance. Prices fluctuated from month to month, especially after the first six months of 1997 . The prices of 1 square meter of a flat were growing by the end of 1999. In 2000-2001 a slight drop was recorded, followed by the further continuation of an uptrend in 2002. Several non-typical units were observed (e.g. May 1997, see: Fig. 5) with a very high price (almost PLN 2,500/1 m²).

To sum up, Japanese candlestick charting can be applied in real estate market observations. It is also a reliable tool of confirming price trends, especially in ex post analysis (as well as a good source of additional information listed above).

However, from the point of view of researchers dealing with the real estate market, Japanese candlestick charting is not free of flaws. The method fails to provide answers concerning real property price levels in individual time intervals. The reasons for such a situation may lie in the specific characteristics of real estate listed below. Yet, it should be noted that similar problems are faced by the vast majority of researchers who study the real estate market (FORYŚ, КОКОт 2001).

1) most real estate buyers who purchase flats are driven by factors other than just their expectations that the price of the flat is going to rise,

2) Japanese candlesticks are drawn on the basis of transaction prices of flats that are similar but not identical, while in the case of the capital market, they are the prices of the same good,

3) the fact that a buyer and a seller have agreed on the terms of transaction does not mean that the notary act will be signed instantly. It often happens that the actual transaction is postponed, thus the price stated in the notary act had in fact been negotiated much earlier,

4) the access to information about individual transaction prices is delayed and limited. Making an investment decision on the basis of outdated prices is impossible.

\section{Reference}

ANGLIN P.M., WiEBe R., 2013, Pricing in an Illiquid Real Estate Market, Journal of Real Estate Research vol. 35, issue 1, pages 83-102.

Betej M., 2013, Catastrophe Theory in Explaining Price Dynamics on the Real Estate Market, Real Estate Management and Valuation. Volume 21, Issue 3, Pages 51-61, ISSN (Online) 1733-2478, DOI: 10.2478/remav-2013-0026, October.

Beracha E., WintoKi M.B., 2013, Forecasting Residential Real Estate Price Changes from Online Search Activity, Journal of Real Estate Research vol. 35, issue 3, pages 283-312.

ChEN M.CH., ChAng Ch.O., YANG CH.Y., HsieH B.M., 2012, Investment Demand and Housing Prices in an Emerging Economy, Journal of Real Estate Research vol. 34, issue 3, pages 345-374.

FORYŚ I., КОкОт S., 2001, Problemy badania rynku nieruchomości (Problems of Real Estate Market Research), Zeszyt naukowy nr 306, Prace KEiS nr 9, Szczecin 2001.

GNAT S. 2011, Zastosowanie wybranych metod prognozowania na rynku nieruchomości (The Application of Selected Methods of the Real Estate Market Forecasting), Journal of the Polish Real Estate Scientific Society Vol. 19, No. 3.

КОкот S., BAS M., 2013, Evaluation of the Applicability of Statistical Methods in Studies on Price Dynamics on the Real Estate Market, Real Estate Management and Valuation. Volume 21, Issue 1, Pages 49-58, ISSN (Online) 1733-2478, DOI: 10.2478/remav-2013-0007, May.

MuRPHY J.J., 1999, Analiza techniczna rynków finansowych (Technical Analysis of Financial Markets), WIGPRESS, Warszawa.

NisSON S., 1991, Japanese candlestick charting techniques: a contemporary guide to the ancient investment technique of the Far East, New York Institute of Finance, New York.

Nisson S., 1996, Świece $i$ inne japońskie techniki analizowania wykresów (Candlestick Charting and Other Japanese Techniques of Chart Analysis), WIGG-PRESS, Warszawa.

Novy-Marx R., 2009, Hot and Cold Markets, Real Estate Economics vol. 37:1 , pp. 1-22.

TARCZYŃSKI W., 1997, Rynki kapitałowe. Metody Ilościowe. (Capital Markets. Quantitative Methods) Vol. I, Placet, Warszawa. 
TrojaneK R., 2013, An Attempt To Identify The Seasonality Of Housing Prices In Selected Polish Cities In 1996-2012, Real Estate Management and Valuation. Volume 21, Issue 4, Pages 96-109, ISSN (Online) 1733-2478, DOI: 10.2478/remav-2013-0041, January. 